\title{
Emma Dononghue's and James Finn Garner's Rebellious Cinderellas: Feminism and Satire for Empowerment in Contemporary Fairy Tales
}

\author{
Maria Amor Barros-del Rio* \\ Faculty of Humanities and Communication, Universidad de Burgos PO box 09001, Burgos, Spain
}

Corresponding Author: Maria Amor Barros-del Rio, E-mail: abarros@ubu.es

\section{ARTICLE INFO}

Article history

Received: February 27, 2017

Accepted: April 27, 2018

Published: September 01, 2018

Volume: 7 Issue: 5

Advance access: July 2018

Conflicts of interest: None

Funding: None

\begin{abstract}
The end of the $20^{\text {th }}$ century witnessed a rewriting of traditional tales for children in English. In 1997, Irish writer Emma Donoghue published Kissing the Witch: Old Tales in New Skins, a sequence of re-imagined fairy tales that was shortlisted for the James L. Tiptree Award. In 1994, American writer James Finn Garner had also re-written many well-known stories for children and had them compiled in a single volume: Politically Correct Bedtime Stories. These new versions of Cinderella incorporate formal, structural and ideological alterations that subvert the traditional fairy tale genre. Using intersectionality as a theoretical research framework, the analysis of these works demonstrates that when the matrix of social power is dissected, the existing networks of oppression are exposed. While both versions are centred around gender, Donoghue and Garner employ different strategies, namely queer alliances and parodic scenes respectively, with the aim of overcoming the same structural obstacles. The resulting characters are rebellious and successful women who challenge tradition and open new horizons for female empowerment through the reinvention of the fairy tale genre.
\end{abstract}

Key words: Fairy Tales, Gender, Intersectionality, Cinderella, Emma Donoghue, James Finn Garner

\section{INTRODUCTION}

Fairy tales have their roots in oral tradition and folklore. They usually refer to cultural conceptions and norms, whilst simultaneously contributing to the construction of perceptions of the self and to the consolidation of a collective imagery within society. In that sense, fairy tales are powerful socialization forces (Parsons, 2004, p. 137) embroidered with relations of power to be implicitly or explicitly transmitted. Over the centuries, legends, novellas and folk stories were gathered and compiled in collections. In particular, versions of Cinderella written by both Perrault (1697) and the Brothers Grimm (1812), while different in development and purpose, have nevertheless been widely read across many generations. In fact, they have become part of the traditional canon because of their universality (Zipes, 2012, p. 17), and it is not unusual to find mixed versions of Cinderella based on these two previous interpretations.

By the end of the $20^{\text {th }}$ century, this folk tale had proliferated and was extensively retold in various literary forms. James Finn Garner re-wrote the tale of "Cinderella", among others, and compiled them in the volume Politically Correct Bedtime Stories: Modern Tales for Our Life and Times, in 1994. In 1997, Emma Donoghue also re-invented this classic tale under the title "The Tale of the Shoe" included in the volume Kissing the Witch. We also have the poetic re-invention of the fairytale in Roald Dahl's "Cinderella" (in Revolting Rhymes, 1982), followed by later interpretations in narrative form including Gail Carson Levine's Ella Enchanted (1998), Donna Jo Naopli's Bound (2004), Gregory Maguire's Confessions of an Ugly Stepsister (1999) and Margaret Peterson Haddix's Just Ella (1999), all of which are worth mentioning here. Adaptations of the original tale for children may also be found in Prince Cinders (1987) by Babette Cole and Cinder Edna (1994) by Ellen Jackson. These new fictional texts are frequently addressed to an adult audience (Altmann \& De Vos, 2001) and challenge tradition both in form and content, in order to "invite readers to reconsider the traditional texts" (Joosen 2011, p. 16). All these literary re-workings share a witty use of parody, irony and aphorisms (Duggan, Hasse \& Callow, 2016, p. 198), draw attention to the interrelation of social and cultural practices and offer alternatives to "dominant ideas of femininity and women's proper role" (Wolff, 1990, p. 61). To better understand some of the formal, structural and ideological novelties of these new Cinderellas, the versions of Irish author Emma Donoghue and American writer James Finn Garner have been chosen for analysis. Their proximity in time of publication and their distant geographical writing context make them suitable for comparison and study.

Concentrating on the gender and social perspectives displayed by these two interpretations, intersectionality is a 
suitable framework to unveil the power-based relations that underlie the traditional tales and the negotiations undertaken by the protagonists to overcome any obstacle to success. Intersectionality has been defined as "the mutually constitutive relations among social identities" (Shields, 2008, p. 301). In other words, intersectionality serves to explore the intersection of spheres and categories of difference such as gender, age, race or class, to name but a few, and to analyse how they interact with one another to create unique positionalities in the matrix of social power, and thus unique experiences of oppression. Intersectionality "is a useful tool to look at the way in which different social divisions inter-relate in terms of the production of social relations and in terms of people's lives" (Anthias, 2013, p. 4). This approach has a twofold purpose, as Warner and Shields have explained:

At the personal level, intersectionality affects the individual's experience of their own social spheres. At the socio-structural level, the individual's legal status, resources, or social needs may advantage them or marginalize them, specifically due to the convergence of identity statuses. (2013: 804)

As intersectionality addresses specificities of identity construction in relation to the axes of social oppression (Lykke, 2010), it is a useful tool for comparative studies. In this case, we seek to expose the networks of oppression that inform the central plots, to detect the emancipatory strategies used to overcome the obstacles as they arise and to assess the novelty of these re-writings in relation with the fairy tale tradition.

\section{CONTEXTUALISATION: OLD CINDERELLAS IN NEW SKINS}

An appropriate contextualization of the challenging aspects in recent versions of Cinderella requires a revision of the frameworks that shaped the original tales. This exercise will serve, on the one hand, to illuminate the limits imposed upon the protagonists, and, on the other, the transgressions and the novelties integrated in the newer versions.

In 1967, Charles Perrault published Cendrillon, the French version of Cinderella. It was written from the transcriptions of oral versions of the tale and it recounts the fall and the resurgence of an abused and vulnerable Cinderella through a succession of events entwined with her destiny. In this version, Cinderella is a passive and distant young woman whose stepsisters mistreat her. Her achievements are a result of the actions of other characters, especially her Fairy Godmother, who magically transforms her so that she can attend the ball, and the Prince who actively searches for the woman whose feet fit the forgotten glass slipper. Noticeably, it is her exit from the domestic realm into the public domain that opens the door for a change in her life. Furthermore, it is her beauty that conquers the Prince who ultimately seeks her out and restores her birthright. Poetic justice is found in the recovery of her high social status through her marriage with the prince. This pinnacle in the social hierarchy is depicted as the ultimate reward for her beauty, self-sacrifice and merciful attitude towards her stepsisters. In Perrault's tale, the almighty social structures of class and marriage are presented as immutable forces that shape Cinderella's fate. As the subject has no capability of negotiation, her position can only be altered by external forces. In the end, the proper organization of social power is restored.

In 1812, the Brothers Grimm recorded Aschenputtel, the German version of Cinderella. This is a more emotional and symbolic adaptation than Cendrillon. The absence of Cinderella's mother is at the core of her helplessness and the cause of her conversations with a hazel tree, a symbol of female wisdom (Parsons, 2004, p. 145), and the birds that nest there. In this version, the reader encounters a tenacious Cinderella who draws her strength from her own wit and is symbolically inspired by the hazel tree and its birds. These symbols which, combined, enact the role of her deceased mother, can be seen as a substitute for Perrault's godmother, and point to the complex psychology and initiative of the main character. In fact, this version of Cinderella is not immersed in submission and passivity; on the contrary, she revolts in rage and anger against her oppressors, an attitude that would have been unthinkable in Perrault's universe. Furthermore, her desire to participate in the public realm is the stimulus for all of her later actions which result in her going to the ball, meeting the Prince and ultimately achieving her goals. She neither submits to her fate nor relies solely on her godmother's help but, on the contrary, she manages to overcome every obstacle that could prevent her from going to the ball, to earn her opportunity to fit in successfully. Thus, her determination to fulfil her wish becomes apparent when she shows eagerness and resolution to try on the little glass slipper and win her prize, namely, marriage to the prince. In this version, human emotions are openly addressed, making the main character appear more credible. Within the narrow limits of her agency, Cinderella shows herself as a prospective match because she knows that marriage is her golden ticket, the only way of escaping the tyranny of her stepsisters and living a more comfortable life. Despite her wit and determination, her reward comes again thanks to her beauty and her social status is restored through the happy ending of married bliss. Although she manages to climb up the social ladder and improve her fate, the plot leads her from family dependence to wedlock.

In contrast with these two traditional models, Emma Donoghue and James Finn Garner offer new appropriations and subversions of the tale of Cinderella. Classified as a thirdwave feminist (Martin, 2010), Emma Donoghue's first story collection, Kissing the Witch: Old Tales in New Skins, has drawn much scholarly attention, particularly within the field of queer studies (Cart, 1997; Dutheil de la Rochere, 2009; Orme, 2010). In this compilation with a feminist perspective, the author reinvents well-known fairy tales applying interesting innovations both in form and content. To begin with, the title challenges conventions and invites the reader to reconsider traditional values. The internal organisation of the book also deserves particular attention: the thirteen tales included in the volume are linked as each story is told by its protagonist to the protagonist of the previous one. As a result, Donoghue offers a new set of interconnected stories of rebellion, transformation, and success. Besides, the author re-names every tale after a significant object or character, 
infusing each story with a new perspective. Thus, Cinderella's story is re-titled "The Tale of the Shoe", the same way "The Tale of the Apple" refers to Snow White and "The Tale of the Needle" to Sleeping Beauty, for example. Undoubtedly, this ploy serves to identify the traditional tale behind the new adaptations tailored by the author. At the same time, it diverts the reader's attention from the protagonist and brings to the fore other elements also relevant in the development of the original plots. This strategy aligns with intersectionality as it opens up a wider perspective and reveals the way in which many elements can intersect and affect the development of the plot. It is not by chance that Emma Donoghue chose "The Tale of the Shoe" to open this collection. The author's intention was clear: to offer alternative possibilities of female emancipation other than the binary patriarchal patterns of social organisation. In fact, several studies affirm that with this tale the author subverts the patriarchal order of a universal feminine destiny within heterosexual wedlock by implementing queer alternatives that lead to success and fulfilment (Riggs, 2016; Dutheil de la Rochère, 2009). Regarding content, "The Tale of the Shoe" focuses on Cinderella's grief for the loss of her mother. Thus, the readership encounters the inner complexities of a character who is no longer unitary and predictable, as in the traditional tales, but ambiguous and contradictory. Her self-imposed seclusion from the outside world keeps her in the domestic realm for a while. Later, in her search for identity, Cinderella follows the pattern of the Brothers' Grimm version and falls for the glamour of the ball and the prospects of finding a suitable partner there. After three disappointing attempts, she finally gets a proposal from the prince but instead of accepting, she panics and runs away. This leads her to the stranger, a much older woman somehow connected with her deceased mother, who had been comforting her after each frustrating attempt at the ball, and who is able to bring out the best in her. The end of the story suggests a fulfilling emotional relationship between the two women.

In the case of Garners' work, the huge success of the fairy tales included in Politically Correct Bedtime Stories has been attributed to the masterful use of irony and satire to overcome social and individual tensions. In this collection, he infuses a counterdiscourse in the tales in order "to debunk a position" (Gring-Pemble \& Watson, 2003, p. 132), that is, he makes readers re-think problematic issues by distorting them. In fact, his literary reworkings could fit the concept of "fractured tales" meaning "an approach used to alleviate biased images" (Gooden \& Gooden, 2001, p. 91), as well as that of "anti-fairy tales" in the sense that they "stress the more negative scenes or motifs, since they appear to be more realistic reflections of the problems of modern society" (Duggan, Hassse \& Callow, 2016, p. 198). In form, he submits to the traditional pattern but in content he incorporates significant variations. This comedian, writer and performer masters satire and does not shy away from pinpointing sensitive issues of current concern. Sarcasm, humor and irony are his linguistic tools for social and political criticism. Consequently, the development of the traditional plot is altered and the outcome is subversive. In Cinderella, he presents an abused young woman who works day and night for her stepmother and stepsisters. Upon the arrival of the invitation for the ball, she is automatically excluded from the hustle and bustle of the preparations, but on the day of the ball, a fairy godperson offers her the suitable paraphernalia i.e. clothing and make-up. She eagerly accepts the opportunity presented to her and attends the event but when she enters the hall she attracts so much attention that the women go green with envy and the men lose control of all basic instincts. Consequently, a huge fight breaks out but when the clock chimes midnight, Cinderella's gown turns into peasant's rags. At this point she demonstrates such delight at her new found bodily freedom that the rest of the women decide to follow in her footsteps and rid themselves of their constrictive garments. As for the men, they continue to fight until they are all dead. At that point, the women take control of the realm, set up a clothing co-op for comfortable garments, lead their business successfully and live happily ever after. Evidently, this plot sneers at traditional gender conventions, throws out the traditional template of a passive and submissive Cinderella, and instead creates a protagonist that mirrors modern day women. Space is made for the depiction of women's opportunities in employment and, more generally, participation in the public domain. Its happy ending presents sisterhood, female empowerment and emancipation as feasible options for women's fulfillment.

\section{FINDINGS AND DISCUSSION}

While different in style and treatment of the classic Cinderella plot, Donoghue's and Garner's reinventions give voice to new possibilities and deviate from correctness and tradition. In light of intersectionality, these re-creations address the social and structural networks of oppression that hinder the protagonist's personal process of emancipation, and offer alternative strategies that circumvent the traditional codes of conduct in the following ways:

\section{The Use of the Narrative Voice}

Instead of following the canon with a distant narrative voice, Donoghue's approach to the Cinderella plot starts at a personal and intimate level. Here, the reader knows Cinderella through a first person narrator who voices her intimate feelings and contradictions. Consequently, in "The Tale of the Shoe", the protagonist's progression in the social ladder is not the main object of interest as was the case in the traditional versions of Perrault and the Brothers Grimm. On the contrary, the narration revolves around Cinderella's grief at the loss of her mother and its multiple consequences. It is through her suffering and her confessional tone that the readership empathizes with Cinderella. And it is through a strong focus on subjective narratives that intersectionality reads the multiple junctions of oppression that can affect the individual. By paying particular attention to Cinderella's loss, Donoghue shortens the distance between the protagonist and the readership and particularises her universe as a unique matrix of subjection.

In Garner's interpretation, "Cinderella" is written in the classic style, with an omniscient narrator that relays the 
story in the past tense. In fact, its beginning, "There once lived a young wommon named Cinderella, whose natural birth-mother had died when Cinderella was but a child" (p. 31), does not forecast major variations in the traditional plot except for some vocabulary alterations. Noticeably, he uses word-play to enhance a parody of the actual notions to which the text refers, in order to intensify the satirical tone of his version of the story. The initial development of the plot maintains some original elements: the young girl is an orphan who lives with her 'mother-of-step' and 'sisters-ofstep'. She is forced to work for them and when the invitation to attend the ball is delivered, she is not allowed to go. But thanks to her 'fairy godperson' (who in this version happens to be a male character), she ends up dressed for the dance. This word game serves to draw attention to the mentioned characters so that the reader senses the author's intention to alter their traditional nature, a device that will unfold during the development of the plot.

Interestingly, the emotional warmth and empathy that Donoghue provokes within the reader is equated by Garner's wit. His version is interspersed with popular cultural elements that suit the contemporary readership and that situate the protagonist in present day life. In Garner's Cinderella, contextualisation covers a wide range of topics that appeal to the readers. These include contemporary icons such as the Barbie doll: "The men stared at and lustered after this wommon who had captured perfectly their Barbie-doll ideas of feminine desirability" (p. 33); the power of the media: "Their first official act was to dress the men in their discarded dresses and tell the media that the fight arose when someone threatened to expose the cross-dressing tendencies of the prince and his cronies"(p. 36); and ethical treatment of animals: "Paint your face with chemicals and make-up that have been tested on nonhuman animals?" (p. 33). In conclusion, it is apparent that both versions manage to capture their readers' interest. They take a timeless tale and convert it into a culturally appropriate modern story of emancipation and female empowerment.

\section{Companionship Versus Individuality}

It is commonly known that Cinderella was a lonely and miserable young woman whose suffering was rewarded in the end with marriage to the prince. The new versions also present a lonesome protagonist but sooner or later the plots overcome the characters loneliness by incorporating varying forms of companionship towards the end of the tale.

As a multiply-marginalized individual, ostracism is present in the life of Donoghue's protagonist, who feels alone and helpless, unable to move forward. In opposition to the traditional versions, the author incorporates a new character, an older woman whose task is to comfort the protagonist and guide her in her emancipatory process using her own wisdom and knowledge. Thus, after each night out dancing Cinderella is assisted by the older woman, who wisely stands by her soothing her tensions. Soon after the arrival of that woman, the protagonist undergoes a personal transformation and marvels at the subtle changes in her self-perception. To express this subjective feeling, the author uses metaphors such as: "How can I begin to describe the transformations? My old dusty self was spun new. This woman sheathed my limbs in blue velvet. I was dancing on points of clear glass" (p. 3). The progressive metamorphosis, as the reader notices, is twofold: it occurs at a subjective level and, at the same time, the protagonist experiences a process of empowerment that places her in a stronger position. This allows Cinderella to go through a healing process at two different levels. In the personal sphere, her self-esteem is restored, as the following sentence exemplifies:

She showed me the sparkle in my eyes" (p. 4); in the structural realm, she progressively acquires a critical awareness of her experiences as oppressive and harmful. To do so, the author uses the shoe as a metaphor in the following words: "What about the shoe? She asked. It was digging into my heel, I told her (pp. 7-8).

In the case of Garner's version, the turning point is found at the sudden transformation of Cinderella's finery into peasant's rags. At the stroke of midnight, she is automatically freed from her uncomfortable, tight and constrictive attire. This unexpected situation startles and captivates the rest of the women who also discard their own oppressive garments in a collective act of liberation. It is interesting to note at this point that all the women at the ball achieve a higher level of freedom, regardless of their origins and prior situations. As intersectional analysis points out, it is necessary to go beyond group-specific identities and connect the particular with the systemic forms of oppression so that a better understanding of its origins, performances and solutions can be achieved (Yuval-Davis, 2011). Here, James Finn Garner succeeds in exposing the multiple forms of oppression women of all kinds are submitted to. Ironically, while the women achieve liberation through rejection of restrictive performances, the men are busy fighting and killing each other. At this tragic point, the use of situational irony relieves the tension of the fight and restores the author's particular view of poetic justice.

\section{Linear and Non-linear Emancipatory Processes}

"The Tale of the Shoe" deviates from the traditional fairy tale in that the process of emancipation of the protagonist is non-linear. Her arduous awakening is hindered by her own compliance with patriarchal norms and submissive behavioural tendencies. This contradictory attitude reaches its peak when the prince finally proposes and she is left speechless. At this point, her muteness is set in contrast with the overwhelming battle that takes place in her head, as the following lines show: "The voices were shrieking, Yes yes yes say yes before you lose your chance you bag of nothingness" (p. 7). Finally, instead of surrendering to social expectations, Cinderella turns towards that older woman who symbolises tenderness and unconditional love. It is then that she finally admits to herself and to the reader: "I had got the story all wrong" (p. 7). The plot is altered and moves on to its climax when the patriarchal norms are challenged; Cinderella and the older woman head together for home, both leading each other on: "So then she took me home, or I took her home, or we were both somehow taken to the closest thing" (p. 8). This 
companionship under equal terms serves to emphasise the uneven relationship between Cinderella and the male characters of the tale. At the end of the tale, the remarkable shift from the use of the singular "I" to the use of (the royal) "we" points to a collective and inclusive future that lies ahead. In terms of space, the mutual decision to go back home symbolises a vindication of the private sphere in terms of freedom and safety. Moreover, this choice radically challenges the conventional pattern for a happy ending and disregards the sufferance that a woman, impersonated here in Cinderella, has to endure to be socially accepted in a male-dominated world. "The Tale of the Shoe" is a personal voyage from the deepest grief and sorrow to self-empowerment and liberation (Crowley \& Pennington, 2010), a progression that some studies have attributed to the use of a "generational collaboration" (Martin, 2010) between a young girl and a mature woman. Apart from this aspect, intersectional analysis indicates that this process owes much to the way the author dissects female experiences of exclusion and subordination in the different spheres. In this rewriting, Emma Donoghue brings to the forefront the intersections of gender, age, class and sexual orientation, in order to offer one of the many "new skins" in which old fairy tales may be re-dressed.

Garner, on the contrary, does not alter the linear progression of Cinderella who, until the clock strikes midnight, follows the traditional pattern. In fact, after that moment, she loses her prominent role in favor of all the women at the ball who take control of the situation and change the traditional ending. They, as a collectivity, design their happy ending through the seizure of power. Thus, it could be affirmed that in Garner's proposal for female emancipation there is more emphasis on the process than on its form, being the outcomes more explicit than in Donoghue's version. His tale is not an elaboration of the personal or collective transformation of a marginalised group. On the contrary, it is the satirical re-writing of female success where fate, instincts and improvisation come together to reverse the patriarchal order of things.

\section{The Female Body as a Problematic Issue}

According to intersectionality research (Choo \& Ferree 2010), the complexity of Cinderella's oppression can be detected when the protagonist is considered within a multiply-marginalized group, namely young, healthy and lowclass single women, together with the interlocking forces that hold the protagonist in a subordinate position. These take the form of conventions and other social practices.

In "The Tale of the Shoe", Cinderella's grieving is accompanied by self-imposed punishment in the form of physically strenuous housework. A sense of personal chaos and disorientation secludes the protagonist from the outside world and keeps her in the domestic realm. Moreover, this loss of direction is enhanced by inner voices (norms of behaviour) that obfuscate a diminishing sense of self. The association between physical confinement and low self-esteem is obvious and indicates how space and social practices intersect in a framework of established conducts that can nullify the subject.
In the Brothers Grimm's version, Cinderella attends the ball three times. Equally, in "The Tale of the Shoe", her persistence symbolizes her attraction to patriarchal gender roles, even though each attempt inflicts increasing damage to her body. So, after Cinderella's first attempt, we read "I kept my belly pulled in" (p. 4); after her second time at the ball, she confesses: "my feet were starting to ache" (p. 5); after her third and last try to fit in, she admits: "I danced like a clockwork ballerina and smiled till my face twisted" (p. 6). Her tenacity at withstanding an unnatural appearance is made explicit in the terminology used to express pain, with words such as "twisted" and "ache", bringing the old conflict between nature and culture to the fore. Furthermore, these scenes imply that within those social structures, Cinderella can only become an eligible debutante if she undergoes the expected physical transformation at a personal cost. The success of these motifs and arguments in the plot has, since Victorian times, been attributed to the triumph of culture over nature exemplified in the transformation of the female (natural) body into "a cultural artefact" (Talairach-Vielmas, 2014: 86). This message is supported by social conventions and codes of behaviour that situate the female subject in an inferior position, as the following example illustrates: "Under the thousand crystal candelabras I danced with elderly gentlemen who had nothing to say but did not let that stop them. I answered only, Indeed and Oh yes and Do you think so?" (p. 4). Even though the ball is a social performance in the public domain, the author conjures up an atmosphere of entrapment by presenting it as the only means to access social integration and marriage. This form of socialization is presented as a deeply stratified scenario where male dominance is unquestioned: "I danced three times with the prince, whose hand wavered in the small of my back" (p. 5). All these passages convey a strong tension that runs through both the personal and social spheres, embedded in a framework of power. This undetectable structure keeps the protagonist in a submissive position.

While Donoghue addresses oppression of the female body from a personal and emotional perspective, Garner uses satire as a rhetorical strategy to deride the patriarchal idealization of female bodies, which in his words is "an unrealistic standard of feminine beauty"(pp. 32-33). To do so, a superior character personified in the fairy godperson, is needed to question with unexpected sharpness the procedures a woman needs to undergo to achieve perfection, as illustrated in the following passage:

Squeeze into some tight-fitting dress that will cut off your circulation? Jam your feet into high- heeled shoes that will ruin your bone structure? Paint your face with chemicals and make-up that have been tested on non-human animals? (p. 33)

This hyperbolic passage, a frequently used rhetorical device, brings again to the fore the concept of the female body "as a cultural artefact" and openly addresses the different forms of violence exerted upon women. As the plot suggests, that kind of beauty is not only physically harmful to the female body but also to the animal world. It is only through the acknowledgement of the female body as "a primary site for the construction and performance of gender" (Reischer 
\& Koo, 2004: 297) that Cinderella's desire to comply with those gendered standards can be situated. She is appreciative of those basic instincts and well aware that she is the object of male desire, as the text shows: "Cinderella was proud of the commotion she was causing" (p. 34). As Kwan and Trautner (2009) have studied, compliance with gendered stereotypes of beauty entails social and personal rewards including positive perceptions of others and higher self-esteem among others. In this version, as well as in Donoghue's re-writing and the original tales, this sort of behaviour is needed in asmuch as it is the only way for the protagonist to move into an established social order, as the following extract suggests: "She walked with head high and carried herself like a wommon of eminent social standing" (p. 34).

In this tale, Garner also directs a convincing and pointed attack on the beauty industry: firstly, he satirizes the process of adjusting to patriarchal conceptions of beauty: "It was like trying to force ten pounds of processed nonhuman animal carcasses into a five-pound skin. Next came immense cosmetic augmentation, which it would be best not to describe at all" (p. 32). Secondly, he refers to the ideological foundations of the cultural representations of beauty: "The womyn (women?), trained at an early age to despise their own bodies, looked at Cinderella with envy and spite" (pp. 3334). Thirdly, he praises the female body when all artifice is shed, so when the women at the ball rid themselves of their constricting dresses, they dance and jump in joy and it is only then that they become "desirable womyn" (p. 36).

In addition to this, Garner takes his criticism of patriarchal values even further, turning the male characters into the victims of their own device. At the sight of Cinderella, their uncontrolled male sexual instincts reach primary levels: she is totally objectified and considered a "prey". Unable to control their "vicious display of testosterone" (p. 35), their anxiety for possession turns into fight resulting in a "macho dance of destruction" (p. 36) and finally "a pile of human animals" (p. 35). The use of zoomorphism at this point is not only shocking but also effective: men are identified with natural and unrestrained instincts, while women take control of the situation. Through this technique, Garner disavows the legitimacy of the masculine upper social classes represented here by the men at the ball. Their behaviour shows irrationality, disorder and violence, according to the text: "something ugly, or at least socially dysfunctional" (p. 34), so the power associated with this group is implicitly revoked. Garner frequently uses satire as a rhetorical strategy to transform gender roles, as in the following example: "Here," he thought, "is a wommon that I could make my princess and impregnate with the progeny of our perfect genes. And thus make myself the envy of every other prince for miles around. And she's blond, too!" (p. 34). The happy ending is also a good example of power differentials:

The womyn clucked their tongues but felt no remorse. The palace and realm were theirs now. [...] Their second was to set up a clothing co-op that produced only comfortable, practical clothes for womyn. Then they hung a sign on the castle advertising CinderWear (for that was what the new clothing was called), and through self-determination and clever marketing, they all - even the mother - and sisters-of-step - lived happily ever after. (p. 36)

As a cautionary note, several studies have alerted against hegemonic conceptualisations of feminism (Ang, 2003; Morris \& Bunjun, 2007; Ristock, 1991) and intersectionality has warned against homogeneity within groups, particularly when they are used as "a code to conceal diversity, presumably in the service of fostering shared identity." (Cole, 2008, p. 250). Thus, this idea of global sisterhood, so obvious in Garner's version, demands careful consideration.

In the end, the women take control of their bodies, a subjective issue symbolized by the recovery of their identity and their possession of the palace. This metaphor of power, where the personal sphere overlaps with the structural domain is subsequently enhanced by their performativity in the business sector, as they set up a successful clothing co-op for practical garments. At this point, the intersection of the different spheres of female participation leads to the presumption of a status convergence. Thus, one might conclude that in Garner's version of Cinderella, success is equated with reconciliation between the different realms. However, a closer reading may show otherwise: although Garner reverses the plot in terms of power forces and women dominate the situation, they remain submitted to an unquestioned economic order that is inevitably sustained by the dominance of one group over the other. In fact, this new version offers a happy ending within the limits of a capitalist economic system, i.e. the success of the new business "through self-determination and clever marketing" (p. 37), leads all the women to live "happily ever after" (p. 37). Thus, it could be argued that the most significant alteration that Garner is able to offer is the replacement of one power group by another, a device that is needed as long as the multiple systemic forms of oppression remain unchanged.

\section{CONCLUSIONS}

A detailed analysis of the selected re-writings demonstrates that both Emma Donoghue's "The Tale of the Shoe" and James Finn Garner's "Cinderella" are transformations of Perrault's and the Brothers Grimm's versions with different endings and most importantly, with different developments. These two tales share a challenging tone regarding the use of terms, conventions, and symbols of hegemonic authority in a patriarchal order. They highlight socially conservative schemes with regard to gender roles and they also pave new pathways for their heroines, at the cost of traditional values.

As the analysis shows, Donoghue and Garner offer different formulas for Cinderella's empowerment that contribute to the re-creation of alternative universes. Their different uses of the narrative voices, their stress upon individual and collective experiences respectively, and their alternative approaches to the development of the plot demonstrate that traditional fairy tales need to keep with the times at the twilight of the $20^{\text {th }}$ century. In these new versions, both Donoghue and Garner manage "to make visible how systems of inequality function in overlapping ways, thus enabling the possibility of transforming these matrices of power" (Warner \& Shields, 2013 , p. 804). At the same time, both authors succeed in di- 
verting the focus of attention from "Cinderella". They make the reader aware of the many other forces that come into play when the subject interacts with everyday practices, namely the relational characteristic of power and the interaction and complexity of processes (Choo \& Ferree, 2010). Thus, the selected tales address distinctive categories such as birthrights and class rights as decisive yet nonetheless surmountable for the heroines to achieve their gradual empowerment.

In "The Tale of the Shoe", Emma Donoghue discloses the multiple forms of oppression that constrain Cinderela's emancipatory process. Her approach from the personal perspective, using the first person narrator and exploring the inner contradictions of the protagonist's psyche, allows the reader to understand the complexity of the individual. This way, the characters of Cinderella in Perrault's and the Brothers Grimm's versions seem overly simplified and, in any case, totally otudated. The confluence of the social and structural spheres, and their effect upon the protagonist are also distinguishable in "The Tale of the Shoe". Conventions and norms force her to fight her loneliness through unwanted heterosexual marriage and social status. Only when confronted with this undesired path does she turn her attention to sisterhood as a liberatory means. Ultimately, the alternative to a pre-determined fate is found in her relation with the older woman. This provides her with the emotional fulfilment she seeks, although it will inevitably be a socially unacceptable relationship that must be kept outside of the system.

Garner, unlike Donoghue's formal novelty, uses the traditional fairy tale formula for the opening and the ending. His main characters are also based on the classic plots. In terms of agency, Garner's Cinderella remains a passive object of other character's interventions, shying away from taking a stand on numerous occasions. But despite this, Garner manages, as does Donoghue in her interpretation, to use irony and satire to denounce the patriarchal power structures that serve to oppress and disempower women. Positioning gender as the central theme, his incisive prose lashes against futile cultural icons, the beauty industry and its effects upon the female body. As a result, he unveils an empty society based upon the culture of image and the immediate satisfaction of the senses.

A common problem that both authors bring to the fore is the many ways violence is exerted upon the female body and the transformations it must undergo to conform to a certain standard. While Donoghue opts for an empowering female companionship, Garner satirizes male behaviour in the form of a zoomorphic parody. Also, both versions coincide in unveiling the complex and frequently unbeatable intersection of systemic structures that validate the norms of behaviour. In Donoghue's adaptation, Cinderella's negotiations and opportunities to achieve personal agency are limited at a social and structural level. The impossibility of overcoming such constraints is solved by a joyful queer relationship that ultimately heals the wounds of life. On the contrary, Garner depicts a world of possibilities for Cinderella and her peers once male lust and testosterone have prompted all the men to kill each other. In his version, women take power in the public realm after rejecting all forms of bodily oppression. Moreover, they achieve wealth and happiness setting up a liberating female garment business.
To conclude, each version of Cinderella embraces a different solution: Garner's tale opts for inclusion within societal norms while Donoghue's alternative re-writing calls for exclusion from patriarchal structures as the only way to achieve female empowerment. These differences are not contradictory but complementary and prove that identities can be both fluid and stable, fixed and changeable, according to different levels of analysis (Shields, 2008, p. 304). If fairy tales are powerful socialization forces and transmitters of cultural values, Emma Donoghue and James Finn Garner have undoubtedly contributed to imagining rebellious, nuanced and complex Cinderellas who are capable of enacting new forms of resistance and innovation, thus paving the pathway to their own emancipation.

\section{REFERENCES}

Altmann, A. E. \& De Vos, G. (2001). Tales Then and Now: More Folktales as Literary Fictions for Young Adults. Colorado: Libraries Unlimited.

Ang, I. (2003). I'm a Feminist But...'Other' Women and Postnational Feminism. In R. Lewis \& S. Mills (Eds.), Feminist Postcolonial Theory: A Reader (pp. 190-206). New York, NY: Routledge.

Anthias, F. (2013). Intersectional what? Social divisions, intersectionality and levels of analysis. Ethnicities, 13.1, 3-19.

Cart, M. (1997). Honoring Their Stories, Too: Literature for Gay and Lesbian Teens. ALAN Review, 25.1, 40-45.

Choo, H. Y. \& Ferree, M.M. (2010). Practicing intersectionality in sociological research: A critical analysis of inclusions, interactions, and institutions in the study of inequalities. Sociological theory, 28.2, 129-149. doi: 10.1111/j.1467-9558.2010.01370.x

Cole, E. R. (2008). Coalitions as a model for intersectionality: From practice to theory. Sex roles, 59.5-6, 443-453. doi: 10.1007/s11199-008-9419-1

Crowley, K. \& Pennington, J. (2010). Feminist Frauds on the Fairies?: Didacticism and Liberation in Recent Retellings of" Cinderella. Marvels \& Tales, 24.2, 297-313.

Donoghue, E. (1997). Kissing the Witch: Old Tales in New Skins. NY: Harper Collins.

Duggan, A. E., Hasse, D. \& Callow, H. J. (2016). Folktales and Fairy Tales. Traditions and Texts from Around the World. Vol. 1. California: Greenwood.

Dutheil de la Rochère, M. H. (2009). Queering the Fairy Tale Canon: Emma Donoghue's Kissing the Witch. In S. R. Bobby (Ed.), Fairy Tales Reimagined: Essays on New Retellings (pp. 13-30). London: MacFarland.

Garner, J. F. (1994). Politically Correct Bedtime Stories. London: Souvenir Press.

Gooden, A. M. \& Gooden, M.A. (2001). Gender representation in notable children's picture books: 1995-1999. Sex roles, 45.1-2, 89-101. doi: 0360-0025/01/0700-0089/0

Grimm, J. \& W. (1812) (2013). Cinderella. Edinburgh: Floris Books.

Gring-Pemble, L. \& Watson, M. S. (2003). The rhetorical limits of satire: An analysis of James Finn Garner's politically correct bedtime stories. Quarterly Journal of Speech, 89.2, 132-153. doi: 10.1080/00335630308175 
Joosen, V. (2011). Critical and Creative Perspectives on Fairy Tales: An Intertextual Dialogue between fairy-tale scholarship and postmodern retellings. Detroit: Wayne State University Press.

Kwan, S. \& Trautner, M. N. (2009). Beauty work: Individual and institutional rewards, the reproduction of gender, and questions of agency. Sociology Compass, 3.1, 4971. doi: 10.1111/j.1751-9020.2008.00179.x

Lykke, N. (2010). Feminist studies: A guide to intersectional theory, methodology and writing. New York: Routledge.

Martin, A. (2010). Generational Collaborations in Emma Donoghue's Kissing the Witch: Old Tales in New Skins. Children's Literature Association Quarterly, 35.1, 4-25.

Morris, M. \& Bunjun, B. (2007). Using intersectional feminist frameworks in research. In Canadian Research Institute for the Advancement of Women (pp. 1-9), Toronto.

Orme, J. (2010). Mouth to mouth: queer desires in Emma Donoghue's Kissing the Witch. Marvels \& Tales, 24.1, 116-130.

Parsons, L. T. (2004). Ella evolving: Cinderella stories and the construction of gender-appropriate behavior. Children's literature in education, 35.2, 135-154. doi: 00456713/04/0600-0135/0

Perrault, C. (1697) (1999). Cinderella. New York: NorthSouth Books.

Reischer, E. \& Koo K.S. (2004). The body beautiful: Symbolism and agency in the social world. Annual Review of Anthropology, 33, 297-317. doi: https://doi.org/10.1146/ annurev.anthro.33.070203.143754
Riggs, A. (2016). Multiple Metamorphoses, or "New Skins" for an Old Tale: Emma Donoghue's Queer Cinderella in Translation. In M. H. Dutheil de la Rochère, G. Lathey \& M. Woźniak (Eds.), Cinderella Across Cultures. New Directions and Interdisciplinary Perspectives (pp. 180196). Detroit: Wayne State University Press.

Ristock, J. (1991). Feminist Collectives: The Struggles and Contradictions in Our Quest for a 'Uniquely Feminist Structure'. In J. Wine \& Ristock J. (Eds.), Women and social change: Feminist activism in Canada (pp. 41-55). Halifax: James Lorimer \& Company.

Shields, S. A. (2008). Gender: An intersectionality perspective. Sex roles, 59.5-6, 301-311. doi: 10.1007/s11199008-9501-8.

Talairach-Vielmas, L. (2014). Fairy Tales, Natural History and Victorian Culture. Palgrave Macmillan, Basingstoke.

Warner, L. R. \& Shields, S.A. (2013). The intersections of sexuality, gender, and race: Identity research at the crossroads. Sex roles, 68.11-12, 803-810. doi: 10.1007/ s11199-013-0281-4

Wolff, J. (1990). Feminine sentences: Essays on women and culture. Cambridge: Polity Press.

Yuval-Davis, N. (2011). Power, intersectionality and the politics of belonging. FREIA Working Paper Series No.75. Aalborg: Feminist Research Centre. http://www.freia. cgs.aau.dk [retrieved: 10/02/2018].

Zipes, J. (2012). The irresistible fairy tale: The cultural and social history of a genre. Princeton University Press. 